\title{
Alberta doctors vote on province-wide medical staff bylaws
}

Published at www.cmaj.ca on Sept. 17

A lberta is poised to become the first province in Canada to have a single, province-wide set of medical staff bylaws. But while the bylaws have been endorsed by the senior leadership of the Alberta Medical Association (AMA), some fear they threaten self-governance of the profession and could compromise doctor-patient relationships.

Previously, individual regions or hospitals came up with their own bylaws. The proposed province-wide bylaws are intended to level the playing field and eliminate local biases, says AMA president Dr. Christopher Doig. "For the first time, there will be a true set of provincewide bylaws where practitioners throughout the province will have the same expectations set upon them."

The proposed bylaws were developed by Alberta Health Services (AHS) and the AMA Provincial Medical Staff Bylaws Working Group. They govern "the terms and conditions on which AHS may grant Practitioners Clinical Privileges; the responsibility of the Medical Staff to AHS for the quality and safety of all professional services provided by Practitioners to Patients and to AHS; the responsibilities of the Medical Staff and AHS to each other for the organization and conduct of the Medical Staff, and in particular the processes relating to Medical Staff Appointments and delineation of Clinical Privileges; and the administrative structures for the governance of Practitioners working in AHS Facilities or other AHS Sites of Clinical Activity" (www.albertadoctors .org/bcm/ama/ama-website.nsf/AllDoc 19582592EFDB0AAA3872577390061 A9F2/\$File/AHS_Medical_Staff_Bylaw s_Sept_1_10.pdf).

They are the product of a "huge consultation" with medical professionals across the province, says Doig. "I would say that the vast majority of the input we received has been positive," he says.

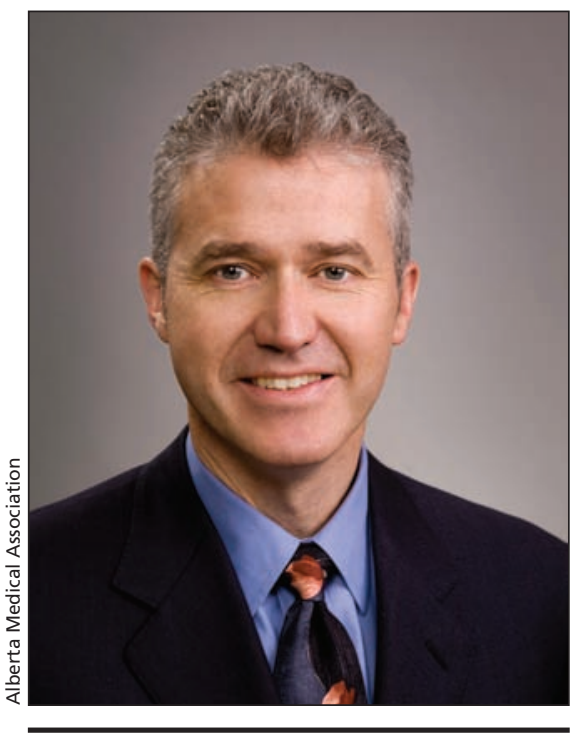

Alberta Medical Association President Dr. Christopher Doig says that "for the first time, there will be a true set of province-wide bylaws where practitioners throughout the province will have the same expectations set upon them."

Not everyone, however, welcomes the proposed bylaws. Dr. Michel Sauve, an Alberta internist, says that the bylaws, if approved, would give the government too much control over the selection of medical leaders in the province, such as chiefs of staff and chiefs of departments, and allow bureaucrats to micromanage patientdoctor relationships. "Under the proposed AHS bylaws, self-governance, which is the only standard of medical governance that protects the integrity of the patient-doctor relationship, will be destroyed," Sauve writes in an email.

The draft Alberta Health Services bylaws have been sent to medical practitioners for ratification and "if there is support, the Board of AHS, who have already endorsed the current draft as being appropriate and ready to be sent out for a vote, will be asked to formally recommend the bylaws to Alberta's Minister of Health for his approval," writes Bruce Conway, AHS media relations advisor, in an email.
If the bylaws do threaten selfgovernance in medicine, this is not a matter to be taken lightly, says Dr. L.R. Huntoon, editor-in-chief of the Journal of American Physicians and Surgeons. "The reason why medical staff selfgovernance is important rather than allowing government bureaucrats to take over governance of the medical profession is really quite simple: physicians are the ones who are qualified to practice medicine, bureaucrats are not," Huntoon writes in an email. "Without medical staff self-governance, there is no quality care. Government bureaucrats typically have other priorities, other than providing optimal care to each individual patient."

Huntoon's opinion is shared by Richard Levenstein, a Florida attorney who represents physicians and hospital medical staff leadership on matters involving licensing, credentialing, medical staff bylaws and issues involving medical practice and patient care in a hospital setting. "Selfgovernance of the medical staff is crucial to the quality of patient care, because it allows the physician responsible for treating a patient to exercise the independent judgment needed to determine what is in the patient's best interest and make recommendations for treatment of a patient without fear of interference with or retaliation for any such decisions by the hospital administration, which is almost always controlled by lay personnel, who are not physicians, and should not be interfering with issues and decisions related to patient care," Levenstein writes in an email. "Where the economic motives and concerns of a government agency or hospital administration clash with physicians' needs to implement quality patient care, the quality of that patient care is sure to be negatively impacted."

According to Doig, however, Alberta medical professionals have nothing to fear. He, too, believes that medical 
professionals are better suited than the government to manage their own profession, and he says that is not going to change. "Self-governance and selfregulation is paramount to the profession and these bylaws, in my opinion, do not take anything away from that," he says.

The AHS also refutes Sauve's claims that self-governance is threatened and that the government intends to take full control of selecting medical leaders. "It is the position of AHS that the proposed bylaws do not reduce selfgovernance of physicians nor will they affect the autonomy of the doctorpatient relationship or the ability of physicians to effectively advocate for their patients," AHS Media Relations Advisor Bruce Conway writes in an e-mail. "AHS believes there is nothing in the draft bylaws that permits government to select medical leaders. As has been the tradition in most of Alberta and Canada for years, medical leaders will be selected through a process that includes significant input by medical staff. There is nothing new or different here." - Roger Collier, CMAJ

DOI:10.1503/cmaj.109-3671 